\title{
Inflammatory Fibroid Polyp in the Jejunum Causing Small Bowel Intussusception
}

\author{
Sung Hoon Kang, Seok Won Kim, Hee Seok Moon, Jae Kyu Sung, Hyun Yong Jeong, Jin Su Kim', \\ Gyu Sang Song ${ }^{2}$ \\ Departments of Internal Medicine, ${ }^{1}$ Surgery, and ${ }^{2}$ Pathology, Chungnam National University School of Medicine, Daejeon, Korea
}

Intussusceptions are defined as the telescoping of one segment of the gastrointestinal tract into an adjacent distal segment. In the small bowel, intussusceptions are typically caused by benign processes, but can occasionally be caused by inflammatory fibroid polyps, which often present as intussusception and bowel obstruction. These polyps are rare, benign, tumorous lesions in the gastrointestinal tract and are typically observed in the stomach, but can occur anywhere in the gastrointestinal tract. Any case of a jejunojejunal intussusception caused by inflammatory fibroid polyps is considered rare, and we report the case of a 51-year-old woman with an inflammatory fibroid polyp of the jejunum presenting as an intussusception who was successfully treated with a resection.

Keywords: Intussusception; Jejunum; Small intestine; Intestinal polyp

\section{INTRODUCTION}

Intussusceptions are defined as the telescoping of one segment of the gastrointestinal tract into an adjacent distal segment and are very rare in adults [1]. Small bowel intussusceptions are typically caused by benign processes [2], and radiologic examinations and endoscopy can be used for their diagnosis. Conservative management of small bowel obstructions includes fluid therapy, electrolyte replacement, and bowel rest. If the obstruction is complete, surgical management should be considered [3].

One possible cause of an intussusception and bowel obstruction is inflammatory fibroid polyps (IFPs), which are rare, benign, tumorous lesions of the gastrointestinal tract. In 1948, Vanek [4] first described this type of polyp as a gastric submucosal granuloma with eosinophilic infiltration. IFPs are most often seen in the stomach, but they can also occur in any segment of the gastro-

Received: November 12, 2014 - Accepted: May 16, 2015

Correspondence to: Hee Seok Moon, M.D.

Department of Internal Medicine, Chungnam National University Hospital, Chungnam National University School of Medicine, 282 Munhwa-ro,

Jung-gu, Daejeon 301-721, Korea

Tel: +82-42-280-8049, Fax: +82-42-257-5753

E-mail:mhs1357@cnuh.co.kr

(c) 2015 The Korean Society of Coloproctology

This is an open-access article distributed under the terms of the Creative Commons Attribution NonCommercial License (http://creativecommons.org/licenses/by-nc/3.0) which permits unrestricted noncommercial use, distribution, and reproduction in any medium, provided the original work is properly cited. intestinal tract, where they most frequently cause an intussusception in the ileum, rather than the jejunum [2]. The pathogenesis of IFPs is unclear, and the most effective treatment for intussusception caused by an IFP is an exploratory laparotomy. Here, we report a rare case of an IFP in the jejunum and presenting as an intussusception.

\section{CASE REPORT}

A 51-year-old woman came to the Emergency Department suffering from epigastric pain, which had been developing for approximately a month. She had no nausea, vomiting, diarrhea, or constipation and had no history of diabetes, hypertension, smoking, or alcohol consumption. She had undergone gastrofibroscopy two weeks prior, and there were no specific findings. She was treated with prokinetic medication, but her symptoms did not improve, and her body weight decreased by two kg over the course of a month

During the preadmission physical examination, her blood pressure, pulse, respiration, and body temperature were 120/70 $\mathrm{mmHg}, 80 \mathrm{bpm}, 20$ per minute and $37^{\circ} \mathrm{C}$, respectively. She appeared chronically ill and had pinkish conjunctiva; her sclera was nonicteric. The patient's abdomen was distended, with tenderness in the periumbilical region, but did not present rebound tenderness. Her bowel sound was increased, and a mass-like lesion was palpable in the area of her lower abdomen. 
Volume 31, Number 3, 2015

Upon laboratory examination, her hemoglobin was $11.8 \mathrm{mg} / \mathrm{dL}$, her hematocrit was $34.9 \%$, and her white blood cell (WBC) count was $11,600 / \mathrm{mm}^{3}$ (85.8\% segmented neutrophils). Total serum bilirubin was $0.36 \mathrm{mg} / \mathrm{dL}$, aspartate aminotransferase was $9 \mathrm{IU} / \mathrm{L}$, alanine aminotransferase was $10 \mathrm{IU} / \mathrm{L}$, albumin was $3.7 \mathrm{~g} / \mathrm{dL}$, and C-reactive protein was $4.2 \mathrm{mg} / \mathrm{dL}$. No specific finding were seen in her chest x-rays, and after her small bowel had been dilated with gas, some air-fluid levels were observed on the abdomen $\mathrm{x}$ ray (Fig. 1). To exclude small bowel obstructions and malignancies, we conducted an abdominal computed tomography (CT) scan. CT results revealed an intussusception of the distal jejunum and a dilatation of the proximal small bowel, although no masslike lesions were found in the small bowel (Fig. 2). Therefore, the patient was diagnosed as having a small bowel obstruction caused by intussusception. She was given decompression treatment using a nasogastric tube and was fed intravenously. Despite the conservative treatment, her abdominal pain and vomiting did not improve; therefore, on the day following admission, she underwent a segmental resection of her small bowel. A grayish polypoid mass measuring $4 \mathrm{~cm} \times 2.8 \mathrm{~cm}$ in size was observed in the jejunal wall (Fig. 3). After microscopic examination, the mass was found to be perivascular spindle cells with eosinophil infiltration (Fig. 4); it

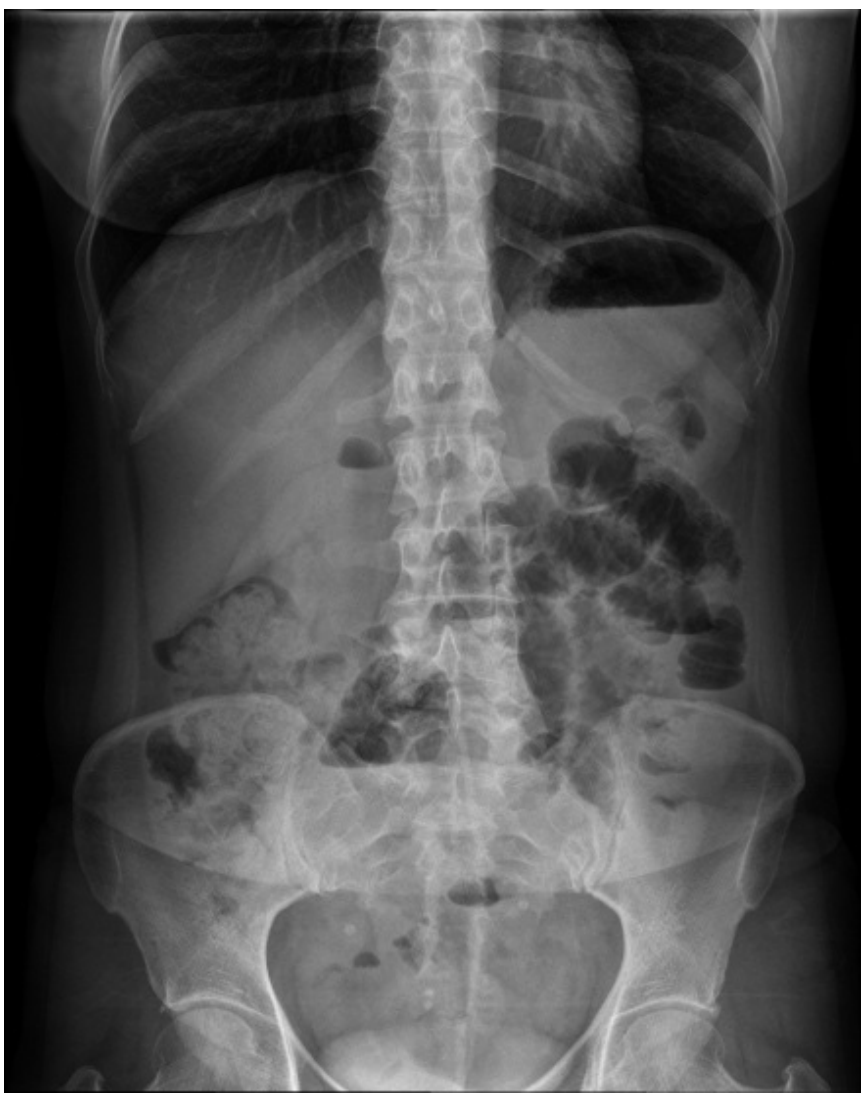

Fig. 1. Abdominal x-ray revealed dilated small bowel segments with some air-fluid levels. was later pathologically confirmed as an IFP. The patient has had no specific complications after surgery.

\section{DISCUSSION}

Adult intussusceptions are very rare and account for only 5\%$16 \%$ of all intussusceptions [5]. In the small bowel, the majority of
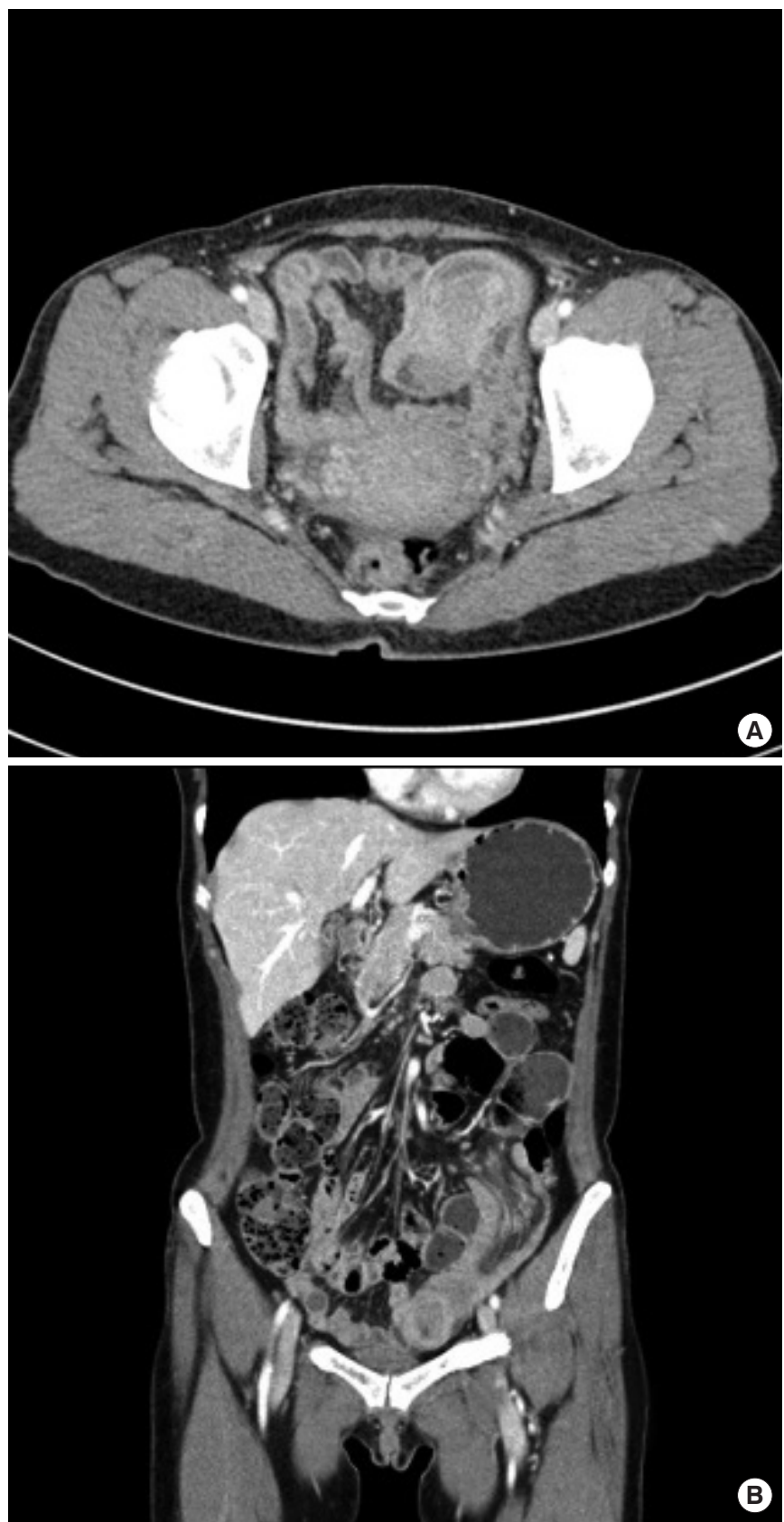

Fig. 2. (A) Abdominal computed tomography (CT) scan showing distal jejunojejunal intussusception and (B) the sagittal section of the same CT scan. 


\section{Coloproctology}

Inflammatory Fibroid Polyp in the Jejunum Causing Small Bowel Intussusception

Sung Hoon Kang, et al.

intussusceptions are caused by benign processes, including IFPs, hematomas, lipomas, leiomyomas, adenomas, Peutz-Jeghers syndrome, adhesions, Meckel's diverticulum, lymphoid hyperplasia, celiac disease, trauma, intestinal duplication, an appendiceal stump, Henoch-Schonlein purpura, and tuberculosis. Several diagnostic modalities can be used to diagnose the presence of small bowel tumors, including small bowel series, enteroclysis, CT scanning, and endoscopy. Capsule endoscopy is a new tool for imaging the small intestine, and its effectiveness and safety were reported by Lewis et al. [6]. Because our patient showed no clinical improvement after conservative management, the patient did not undergo any of these visualization tests and was instead immediately operated upon.

IFPs are rare, benign, neoplastic lesions of the gastrointestinal tract, which have been referred by names such as an eosinophilic granuloma, a hemangiopericytoma, a polypoid fibroma, a gastric

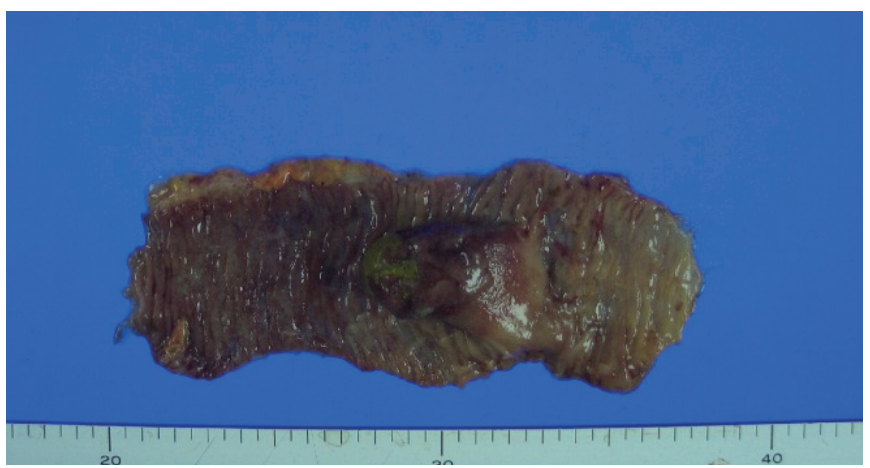

Fig. 3. A grayish polypoid mass, measuring $4 \mathrm{~cm} \times 2.8 \mathrm{~cm}$ in size that was removed from the jejunum. fibroma with eosinophilic infiltration, eosinophilic gastroenteritis, a polyp with eosinophilic granuloma, and an inflammatory pseudo-tumor. Helwig and Ranier [7] proposed the term IFP in 1953, and it has gained acceptance since. IFPs can be found in any age group, but peak incidence is between the sixth and seventh decades, and IFPs occur slightly more frequently in males [8]. All six cases of IFPs reported by Vanek [4] occurred in the stomach, where IFPs most frequently occur, particularly in the gastric antrum. Although less frequently, IFPs do occur in the distal ileum and very rarely in the colon, jejunum, duodenum, and esophagus [8].

Clinical presentation varies by location and size, although IFPs of the stomach and colon are typically asymptomatic and are generally discovered by endoscopy or during a laparotomy [9]. When they occur in the small bowel, they can cause abdominal pain, lower gastrointestinal bleeding, anemia, and rarely bowel obstruction due to intestinal intussusceptions.

The pathogenesis of IFPs remains unclear [2]. In the first described case, Vanek [4] suggested allergic processes as possible factors because eosinophilia had been observed in many of the lesions. Neural hyperplasia, the formation of granulation tissues, irritants, trauma, and genetics, as well as bacterial, physical, and chemical stimulants, have also been suggested $[2,4,10]$. Generally, IFPs are grey, sessile, or pedunculated polypoid lesions that arise from the submucosa into the lumen of the bowel, often with the ulceration of the overlying mucosa. IFPs typically measure 2-5 $\mathrm{cm}$ in diameter, although giant IFPs larger than $20 \mathrm{~cm}$ have been reported.

Histologically, IFPs are characterized by inflammatory infiltrates (predominantly eosinophils) and the localized proliferation of mononuclear spindle-shaped cells [10]. Gastric IFPs are treated with endoscopic removal, and all 85 cases of small bowel IFPs re-
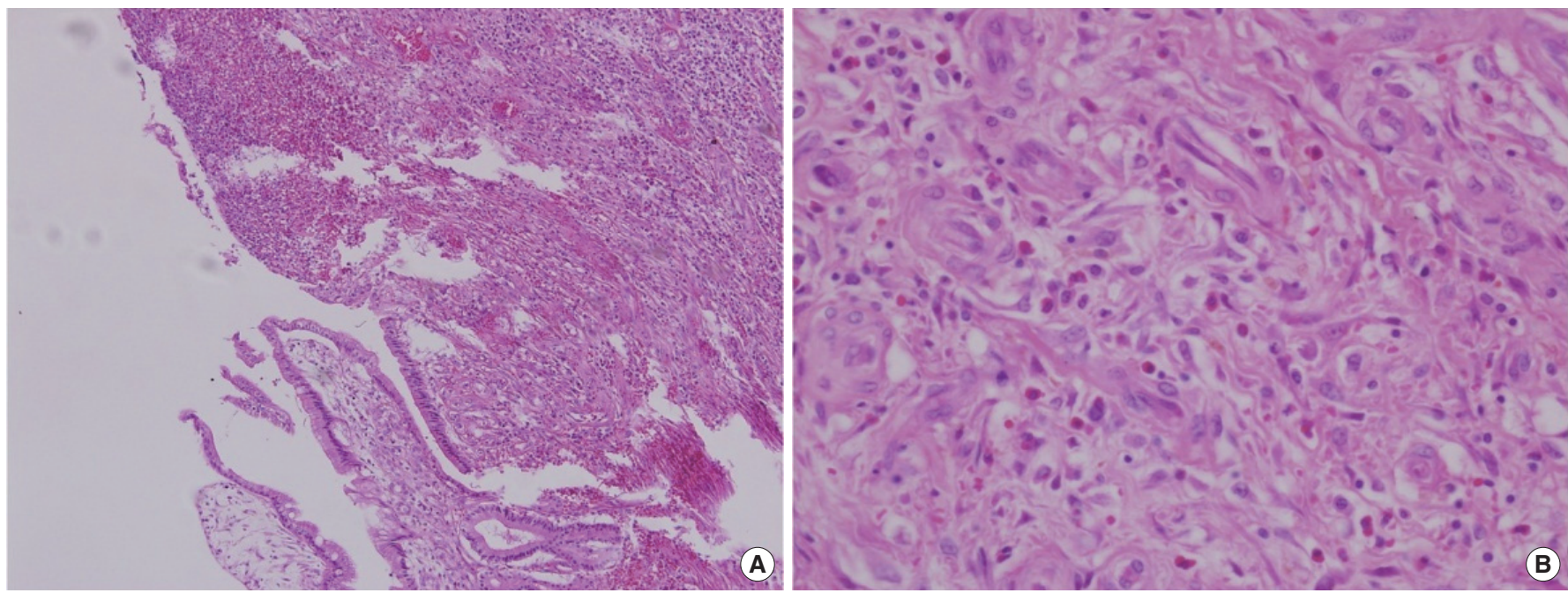

Fig. 4. Microscopic findings revealed (A) a normal mucosal layer of the jejunum (lower half of the image) and an apparently-destroyed mucosal layer (upper half) $(\mathrm{H} \& \mathrm{E}, \times 100)$, as wells as $(\mathrm{B})$ small vessels with perivascular spindle cells and inflammation with eosinophil infiltrates $(\mathrm{H} \& \mathrm{E}, \times 400)$. 
ported from 1976 to 2011 were treated by surgical resection [2]. Intussusception caused by an IFP is best treated with an exploratory laparotomy, because IFPs do not recur after surgical resection.

In conclusion, we have described a rare case of intussusception caused by IFP, where surgical resection was necessary to alleviate the patient's symptoms.

\section{CONFLICT OF INTEREST}

No potential conflict of interest relevant to this article was reported.

\section{REFERENCES}

1. Agha FP. Intussusception in adults. AJR Am J Roentgenol 1986; 146:527-31.

2. Akbulut $\mathrm{S}$. Intussusception due to inflammatory fibroid polyp: a case report and comprehensive literature review. World J Gastroenterol 2012;18:5745-52.
3. Fevang BT, Jensen D, Svanes K, Viste A. Early operation or conservative management of patients with small bowel obstruction? Eur J Surg 2002;168:475-81.

4. Vanek J. Gastric submucosal granuloma with eosinophilic infiltration. Am J Pathol 1949;25:397-411.

5. Eisen LK, Cunningham JD, Aufses AH Jr. Intussusception in adults: institutional review. J Am Coll Surg 1999;188:390-5.

6. Lewis BS, Eisen GM, Friedman S. A pooled analysis to evaluate results of capsule endoscopy trials. Endoscopy 2005;37:960-5.

7. Helwig EB, Ranier A. Inflammatory fibroid polyps of the stomach. Surg Gynecol Obstet 1953;96:335-67.

8. de la Plaza R, Picardo AL, Cuberes R, Jara A, Martinez-Penalver I, Villanueva MC, et al. Inflammatory fibroid polyps of the large intestine. Dig Dis Sci 1999;44:1810-6.

9. Rehman S, Gamie Z, Wilson TR, Coup A, Kaur G. Inflammatory fibroid polyp (Vanek's tumour), an unusual large polyp of the jejunum: a case report. Cases J 2009;2:7152.

10. Wysocki AP, Taylor G, Windsor JA. Inflammatory fibroid polyps of the duodenum: a review of the literature. Dig Surg 2007;24:162-8. 